\title{
The regulation of p53, p38 MAPK, JNK and XBP-1s by sphingosine kinases in human embryonic kidney cells
}

\author{
Mariam Alsanafi, Samuel L. Kelly', Melissa McNaughton, Alfred H. Merrill Jr', \\ Nigel J Pyne, Susan Pyne*
}

Strathclyde Institute of Pharmacy and Biomedical Sciences, University of Strathclyde, 161 Cathedral St, Glasgow, G4 0RE, Scotland, UK, ' School of Biological Sciences and Petit Institute for Bioengineering and Bioscience, Georgia Institute of Technology, Atlanta, Georgia, USA

Short Title: Regulation of p53, p38 MAPK, JNK and XBP-1s by sphingosine kinases

Key words: Sphingosine kinase, dihydroceramide desaturase, sphingosine 1-phosphate, ER stress, proteasome

* To whom correspondence should be addressed (email: susan.pyne@strath.ac.uk)

Abbreviations: ABC294640, 3-(4-chlorophenyl)-adamantane-1-carboxylic acid (pyridin-4ylmethyl)amide; CerS, ceramide synthase; Degs1, dihydroceramide desaturase; ER, endoplasmic reticulum; JNK, c-Jun N-terminal kinase; MAPK, mitogen activated protein kinase; MG132, carbobenzoxy-Leu-Leu-leucinal; NAC, N-acetyl-L-cysteine; PARP, Poly(ADP-Ribose) Polymerase; S1P, sphingosine 1-phosphate; SK1, sphingosine kinase 1; SK2, sphingosine kinase 2; SKi, 2-(p-hydroxyanilino)-4-(p-chlorophenyl)thiazole; UPR, unfolded protein response; XBP-1s, X-box protein-1s. 
ABSTRACT--Since inhibitors of sphingosine kinases (SK1, SK2) have been shown to induce p53-mediated cell death, we have further investigated their role in regulating p53, stress activated protein kinases and XBP-1s in HEK293T cells. Treatment of these cells with the sphingosine kinase inhibitor, SKi, which fails to induce apoptosis, promoted the conversion of p53 into two proteins with molecular masses of 63 and $90 \mathrm{kDa}$, and which was enhanced by over-expression of ubiquitin. The SKi induced conversion of p53 to p63/p90 was also enhanced by siRNA knockdown of SK1, but not SK2 or dihydroceramide desaturase (Degs1), suggesting that SK1 is a negative regulator of this process. In contrast, another sphingosine kinase inhibitor, ABC294640 only very weakly stimulated formation of p63/p90 and induced apoptosis of HEK293T cells. We have previously shown that SKi promotes the polyubquitination of Degs1, and these forms positively regulate p38 MAPK/JNK pathways to promote HEK293T cell survival/growth. siRNA knockdown of SK1 enhanced the activation of p38 MAPK/JNK pathways in response to SKi, suggesting that SK1 functions to oppose these pro-survival pathways in HEK293T cells. SKi also enhanced the stimulatory effect of the proteasome inhibitor, MG132 on the expression of the pro-survival protein XBP1s and this was reduced by siRNA knockdown of SK2 and increased by knockdown of p53. These findings suggest that SK1 and SK2 have opposing roles in regulating p53-dependent function in HEK293T cells. 


\section{Introduction}

The bioactive lipid, sphingosine 1-phosphate (S1P) is formed by the phosphorylation of sphingosine by two isoforms of sphingosine kinase (SK) termed SK1 and SK2 that are encoded by distinct genes. The enzymes exhibit different sub-cellular localisations and are involved in regulating overlapping and non-overlapping biology in cells [1]. S1P is irreversibly degraded by S1P lyase to produce (E)-2-hexadecenal and phosphoethanolamine or is reversibly dephosphorylated to reform sphingosine by S1P phosphatase or lipid phosphate phosphatase [1]. Alternatively, S1P is transported out of cells and binds to a family of G protein-coupled receptors

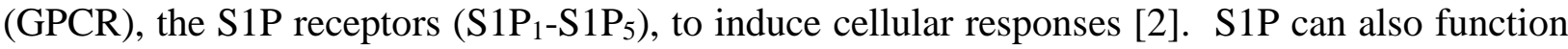
inside cells by binding to proteins such as HDAC-1/2 and prohibitin to regulate intracellular signaling responses $[3,4]$. SK can also catalyse the phosphorylation of dihydrosphingosine to produce dihydrosphingosine 1-phosphate [1]. This is significant as it suggests that the enzyme can modulate de novo synthesis of ceramide which involves, in the last step, the introduction of a trans 4,5 double bond into dihydroceramide by dihydroceramide desaturase (Degs1).

There is evidence that SK inhibitors induce apoptosis of cells via a p53-dependent mechanism. For instance, Lima et al. [5] have demonstrated that the SK1-selective inhibitor, SK1-I, an analogue of sphingosine, suppressed cancer cell growth and clonogenic survival in a p53dependent manner. This involved an SK1-I-induced phosphorylation of p53 on Ser15 to enhance its transcriptional activity and induce expression of BAX, BAK1, and BID. SK1 inhibition also increased vacuoles, enhanced BECN- and ATG5-dependent autophagy, and increased cell death via a p53-dependent mechanism. In addition, we and others have found that certain inhibitors of sphingosine kinase (e.g. SKi (2-(p-hydroxyanilino)-4-(p-chlorophenyl)thiazole) [6] and ABC294640 (4-chlorophenyl)-adamantane-1-carboxylic acid (pyridin-4-ylmethyl)amide) modulate Degs1 expression in androgen-independent prostate cancer cells [6, 7]. Both SKi and 
ABC294640 promote senescence associated with the proteasomal degradation of SK1 and Degs1 and increased p53 expression [6]. Indeed, treatment of cancer cells with SKi or ABC294640 results in increased dihydroceramide levels [7, 8-10] possibly due to the proteasomal degradation and removal of Degs1 from these cells. p53 has also been reported to induce a caspase-2dependent proteolysis of SK1 [11] and p53 mutations are prevalent in many cancers, including triple negative breast cancer, where SK1 is resistant to proteolysis, thereby conferring a survival advantage to these cancer cells.

SK1, SK2 and Degs1 have been reported to both promote and inhibit apoptosis, and we consider that this might be dependent on the functional interaction between these enzymes in a cell context specific manner. For instance, Degs1 deficiency produces an anti-apoptotic effect via activation of AKT and autophagy [12], while others have shown that Degs1 inhibition promotes cell death $[13,14]$. Thus, apoptosis is induced by fenretinide and resveratrol, which reportedly inhibit Degs1 activity [15-17] and this is prevented by blockade of enzymes up-stream of Degs1 in the de novo ceramide synthesis pathway [16]. SK1 is widely associated with cell survival, while SK2 has been shown to promote apoptosis. In the latter case, SK2 contains a BH3 domain that sequesters antiapoptotic $\mathrm{Bcl} 2$ to promote apoptosis [18]. However, others have reported that pharmacological inhibition of SK2 activity promotes apoptosis in various cancer cells (for review, see [19]).

We recently reported that Degs1 is subject to polyubiquitination induced by the SK inhibitor, SKi in HEK293T cells [20]. The polyubiquitinated forms of Degs1 accumulate as they transit to proteasomal degradation and exhibit a 'gain of function', which is linked with the activation of pro-survival pathways, including phosphorylation of p38 MAPK and JNK and increased expression of X-box protein-1s (XBP-1s) in these cells [20]. In contrast, the SK inhibitor, ABC294640 fails to induce polyubiquitination of Degs1 at a concentration that increases de novo 
synthesis of ceramide and induces apoptosis via a Degs1-dependent mechanism [20]. These findings suggest that the native and polyubiquitinated forms of Degs1 have opposing functions in terms of cell survival. There is also evidence for similar regulation of ceramide synthase 1 (CerS1) by the ubiquitin-proteasome degradation pathway. For instance, stress induces translocation of CerS1 from the ER to Golgi and promotes its proteasomal degradation in HEK293 cells [21]. Moreover, over-expression of CerS1 increases the activation of p38 MAPK by cisplatin in HEK293 cells [22]. Therefore, we have further investigated the effect of SKi on the survival of HEK293T cells in terms of the functional roles of SK1, SK2 and Degs1 and their regulation of p53, p38 MAPK, JNK and XBP-1s pathways.

\section{Materials and Methods}

2.1 Materials--All general biochemicals were from Sigma (Poole, UK). SKi (SKI-II [23], 567731) was from Merck Biosciences (Nottingham, UK). ABC294640 ([24], S7174) was from Stratech Scientific (UK). MG132 (C2211), N-acetyl-L-cysteine (A7250) and Protein G Sepharose ${ }^{\circledR}$, Fast Flow (P3296) were from Sigma (Poole, UK). Anti-GAPDH (sc-47724) antibody was from Insight Biotechnology Ltd (Wembley, UK); anti-p53 (P8999) antibody was from Sigma (Poole, UK); antiDegs1 (ab185237) antibody was from Abcam; anti-phospho-SAPK/JNK (4671), anti-phosphop38 MAPK (9211), anti-PARP (9542) and anti-XBP-1s (12782) antibodies were from New England Biolabs Ltd. (Hitchin, UK). Anti-SK1 antibody was custom made by Abcam [25]. DharmaFECT ${ }^{\mathrm{TM}}$ reagent, ON-TARGETplus SMARTpool ${ }^{\circledR}$ siRNAs for p53, Degs1, SK1 and SK2 were from Dharmacon (Cromlington, UK). Scrambled siRNA (ALLSTARS Negative control) was from Qiagen (Crawley, UK). HA-Ubiquitin plasmid (18712) construct was from Addgene (Teddington, UK). [Methyl- ${ }^{3} \mathrm{H}$ ] thymidine (25Ci/mmol; 37MBq/ml) (NET027A) was from PerkinElmer (Beaconsfield, UK). 
2.2 Cell Culture--HEK293T cells were maintained in DMEM/Glutamax supplemented with 50 $\mathrm{U} / \mathrm{ml}$ penicillin, $50 \mu \mathrm{g} / \mathrm{ml}$ streptomycin and $10 \%$ (v/v) foetal bovine serum at $37^{\circ} \mathrm{C}$ with $5 \% \mathrm{CO} 2$.

$2.3\left[{ }^{3} \mathrm{H}\right]$-Thymidine incorporation--HEK293T cells (approx. 70\% confluent) in 24 well plates were incubated with compounds or vehicle (DMSO, 0.1\% v/v final), as detailed in the figure legends, for 20 hours prior to the addition of $\left[{ }^{3} \mathrm{H}\right]$-thymidine $(9.25 \mathrm{kBq}$ per well) for a further 5 hours. Incubations were terminated by removing the medium and immediately adding $1 \mathrm{ml}$ of ice cold $10 \%(\mathrm{w} / \mathrm{v})$ trichloroacetic acid and placed on ice for 10 minutes. This was replaced with a further $1 \mathrm{ml}$ ice cold 10\% (w/v) trichloroacetic acid for 10 minutes and repeated once more. Residual nuclear material was dissolved in $0.25 \mathrm{ml}$ of $0.1 \%$ SDS/0.3 M NaOH. [3H]-thymidine uptake was quantified by liquid-scintillation counting. Radiometric values (mean \pm SD) were obtained from 3 or more independent experiments.

2.4 siRNA Transfection--HEK293T cells were transiently transfected with siRNA constructs or scrambled siRNA (as a negative control) at a final concentration of $100 \mathrm{nM}$. Cells were grown to approximately $70 \%$ confluence and for three wells a mixture of $1 \mu \mathrm{M}$ siRNA in $175 \mu \mathrm{l}$ of antibiotic-free DMEM/Glutamax medium and $2.8 \mu$ of DharmaFECT® 2 transfection reagent in 172.2 $\mu \mathrm{l}$ of antibiotic-free DMEM/Glutamax medium was prepared. These preparations were incubated for 5 minutes at room temperature to mix and then combined and incubated for 20 minutes at room temperature to allow formation of siRNA and DharmaFECT® 2 transfection reagent complexes. Next, $1.4 \mathrm{ml}$ of antibiotic-free DMEM/Glutamax medium supplemented with $10 \%(\mathrm{v} / \mathrm{v})$ foetal bovine serum was added to the $350 \mu \mathrm{l}$ transfection mixture and mixed gently. 500 $\mu \mathrm{l}$ of transfection mixture was then used to replace the medium of each well and cells were incubated at $37^{\circ} \mathrm{C}$ in $5 \% \mathrm{CO}_{2}$ for 48 hours. 
2.5 Transient cell transfection--HEK293T cells were transiently transfected with plasmid constructs or vector (pcDNA3.1) as control. For each well of cells to be transfected, $1 \mu \mathrm{g}$ of the HA-ubiquitin plasmid (or vector) and $1.5 \mu 1$ of Lipofectamine ${ }^{\mathrm{TM}} 2000$ were diluted separately in $200 \mu \mathrm{l}$ of serum free media and incubated at room temperature for 20 minutes. $800 \mu \mathrm{l}$ of DMEM/Glutamax antibiotic free media supplemented with 1\% (v/v) of foetal bovine serum was then added and used to replace the medium of each well. Cells were incubated at $37^{\circ} \mathrm{C}$ in $5 \% \mathrm{CO} 2$ for 8 hours. Medium was then replaced with DMEM/Glutamax supplemented with $10 \%(\mathrm{v} / \mathrm{v})$ of foetal bovine serum and treated, as required, for 24 hours.

2.6 Immunoprecipitation--Cells (from 3 wells) were placed in $500 \mu$ ice-cold lysis buffer (containing $137 \mathrm{mM} \mathrm{NaCl}, 2.7 \mathrm{mM} \mathrm{KCl}, 1 \mathrm{mM} \mathrm{MgCl}$, $1 \mathrm{mM} \mathrm{CaCl}$, 1\% (w/v) Na deoxycholate, 10\% (v/v) Glycerol, 20 mM Tris-Base, $1 \mathrm{mg} / \mathrm{ml} \mathrm{BSA,} 0.5 \mathrm{mM} \mathrm{Na}_{3} \mathrm{VO}_{4}, 0.2 \mathrm{mM}$ PMSF, leupeptin and aprotinin (both at $10 \mu \mathrm{g} / \mathrm{ml}$ ); $\mathrm{pH}$ 8.0). The samples were homogenised through a $0.24 \mathrm{~mm}$ gauge needle and syringe and incubated at $4^{\circ} \mathrm{C}$ for 60 minutes. The cell lysate was centrifuged (22000 $\mathrm{g}, 4^{\circ} \mathrm{C}, 10$ minutes) and $250 \mu \mathrm{l}$ of the supernatant pre-cleared using $20 \mu \mathrm{l}$ of lysis buffer: protein G Sepharose beads (50:50) $\left(4^{\circ} \mathrm{C}, 20\right.$ minutes). The supernatant $(200 \mu \mathrm{l})$ was subjected to immunoprecipitation by adding $2 \mu \mathrm{l}$ of anti-p53 antibody and $20 \mu 1$ protein G Sepharose beads $\left(4^{\circ} \mathrm{C}, 2\right.$ hours). The resulting immunoprecipitate was washed three times with Buffer A (containing $10 \mathrm{mM}$ HEPES, $100 \mathrm{mM} \mathrm{NaCl}, 0.5 \%$ (v/v) NP-40 and $0.2 \mathrm{mM}$ PMSF; pH 7.0) and three times with Buffer B (Buffer A without NP-40). Finally, the immunoprecipitate was retrieved from the beads using $20 \mu \mathrm{l}$ Laemmli buffer (0.125 M Tris-HCl, 10\% (v/v) 2-mercaptoethanol, 20\% (v/v) glycerol, 4\% (w/v) SDS and 0.004\% (w/v) bromophenol blue; $\mathrm{pH} 6.7)$ (100 ${ }^{\circ} \mathrm{C}, 3$ minutes) and subjected to SDS-PAGE. 
2.7 Western Blotting--After required treatments, HEK293T cells were lysed in sample buffer (62.5 mM Tris-HCl (pH 6.7), $0.5 \mathrm{M}$ sodium pyrophosphate, $1.25 \mathrm{mM}$ EDTA, 1.25\% (w/v) sodium dodecyl sulphate, 0.06\% (w/v) bromophenol blue, 12.5\% (v/v) glycerol, $50 \mathrm{mM}$ dithiothreitol) and proteins resolved on a $10 \%$ (v/v) acrylamide/bisacrylamide gel, and transferred to nitrocellulose Hybond membrane (GE Healthcare). Membranes were blocked in 5\% (w/v) bovine serum albumin in Tris-buffered saline with Tween (TBST; 20 mM Tris-HCl (pH 7.5), $48 \mathrm{mM} \mathrm{NaCl,} \mathrm{0.1 \%} \mathrm{(v/v)}$ Tween 20) for 1 hour at room temperature prior to incubation with primary antibody (diluted in blocking buffer) overnight at $4^{\circ} \mathrm{C}$. Following three washes in TBST, membranes were incubated with horse radish peroxidase conjugated anti-mouse or anti-rabbit IgG secondary antibody (diluted in blocking buffer) for 1 hour at room temperature. Immuno-reactive protein bands were visualised using enhanced chemiluminescence, acquired as TIFF files and quantified using ImageJ.

2.8 Lipidomics--HEK293T cells were treated with vehicle (DMSO, 0.1\% v/v final), SKi (10 $\mu \mathrm{M})$ and/or SK1 or SK2 siRNA for 24 hours, then carefully rinsed twice with $1 \mathrm{ml}$ ice cold phosphate buffered saline (PBS) before being scraped into ice cold PBS. Cells were pelleted by centrifugation (180 $\mathrm{g}, 4^{\circ} \mathrm{C}, 3$ minutes) and the supernatant carefully removed. The cell pellet was snap frozen in liquid nitrogen for 5 seconds before being stored in $-80^{\circ} \mathrm{C}$ for sphingolipid analysis, which was conducted as described previously [26, 27] using liquid chromatography, electrospray-ionization tandem mass spectrometry and multiple reaction monitoring for quantitation.

2.9 Densitometry--Densitometric analysis was performed using Image J software program (Scion Corporation, Frederick, MD), expressed as the ratio of protein of interest versus GAPDH and represented as mean +/- SEM for \% changes of three separate experiments. Statistical analysis was undertaken using one way ANOVA and Bonferroni’s multiple comparison test. 


\section{Results and Discussion}

3.1 Post-translational modification of p53 in HEK293T cells--Since SK1 inhibitors have been shown to induce p53-mediated cell death [5], we have investigated the role of SK1, SK2 and Degs1 in regulating p53 expression/function in HEK293T cells. p53 is expressed in HEK293T cells, along with low levels of a protein with a molecular mass of $63 \mathrm{kDa}$ that cross-reacted with the antip53 antibody (Fig. 1). We first assessed whether the SK1/2 inhibitor SKi ((2-(p-hydroxyanilino)4-(p-chlorophenyl)thiazole)) [23], which fails to induce apoptosis of HEK293T cells [20] had any effect on p53 expression levels. In this regard, treatment of HEK293T cells with SKi induced the formation of p63 and an additional protein with a molecular mass of $90 \mathrm{kDa}$ that cross-reacted with the anti-p53 antibody (Fig. 1). In contrast, treatment of HEK293T cells with the SK2 inhibitor, ABC294640 ((4-chlorophenyl)-adamantane-1-carboxylic acid (pyridin-4-ylmethyl)amide) [24], which induces apoptosis of HEK293T cells [20], only very weakly stimulated formation of p63 and p90 (Fig. 1). Identical results were obtained with the parental HEK293 cell line (data not shown).

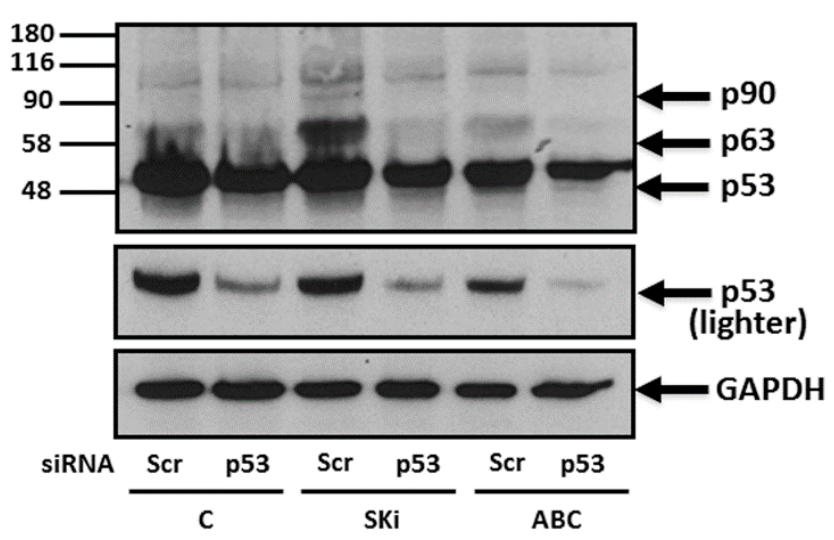

Fig. 1 Effect of ABC294640 or SKi on p53 in HEK293T cells. Cells maintained in serum and grown to $70 \%$ confluence were treated scrambled or p53 siRNA (100 nM) for 48 h prior to treatment with ABC294640 $(25 \mu \mathrm{M})$ or SKi $(10 \mu \mathrm{M})$ for $24 \mathrm{~h}$. Western blot probed with anti-p53 antibody showing the effect of SKi or ABC294640 and/or p53 siRNA on p53, p63 and p90 expression levels. A lighter exposed p53 blot is shown to better typify the reduction in native p53 expression with p53 siRNA. Blots were re-probed for GAPDH using anti-GAPDH antibody to 
ensure comparable protein loading. Results are representative of at least 3 independent experiments.

To confirm the identity of p63 and p90 as potential post-translationally modified forms of p53, we treated cells with p53 specific siRNA to knockdown the expression of p53. As well as reducing p53 expression, the treatment with p53 siRNA removed both p63 and p90 from SKi-treated HEK293T cells (Fig. 1), suggesting these proteins are, indeed, post-translationally modified forms of p53. We also used an immunoprecipitation protocol with anti-p53 antibody as a second independent method of identification. p53, p63 and p90 are present in the 'high-speed' pellet fraction of SKi-treated cells and were solubilised with deoxycholate containing buffer (data not shown). Using this methodology, p53, p63 and p90 were immunoprecipitated with the anti-p53 antibody from SKi-treated cells (Fig. 2), thereby confirming that p63 and p90 are p53 related proteins. Furthermore, in addition to p63 and p90, higher molecular mass protein bands between 90 and 180 kDa are present in anti-p53 immunoprecipitates; detected with anti-p53 antibody (Fig. 2). These are likely detectable as a consequence of concentrating the cellular p53 material in the immunoprecipitate. These data are consistent with p53 being subject to ubiquitin-proteasomal degradation

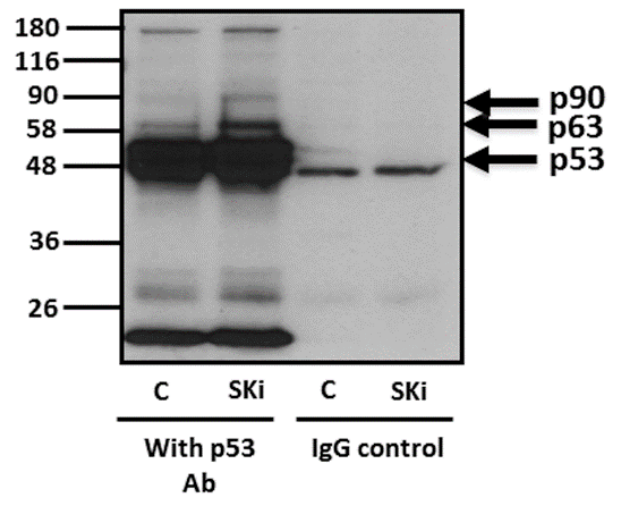

Fig. 2 Identification of post-translationally modified forms of p53 in HEK293T cells. Cells maintained in serum and grown to $70 \%$ confluence were treated with SKi (10 $\mu \mathrm{M})$ for $24 \mathrm{~h}$. 
Western blot probed with anti-p53 antibody showing the presence of p53, p63 and p90 in anti-p53 immunoprecipitates. Results are representative of at least 3 independent experiments.

We have excluded phosphorylation as a possible mechanism for post-translational modification based on failure to detect p63 or p90 with an anti-phospho-p53 antibody (data not shown). In order to assess whether the post-translational modification involves ubiquitination, we transfected HEK293T cells with a plasmid construct encoding HA-ubiquitin to establish whether this might enhance formation of p63 and p90 in response to SKi. This was indeed the case (Fig. 3), presumably due to increased availability of ubquitin for the E3 ligase responsible for catalysing the ubiquitination of p53. Therefore, it is not unreasonable to suggest that removal of p53 by the ubiquitin-proteasomal degradation will likely induce a loss of function of p53.
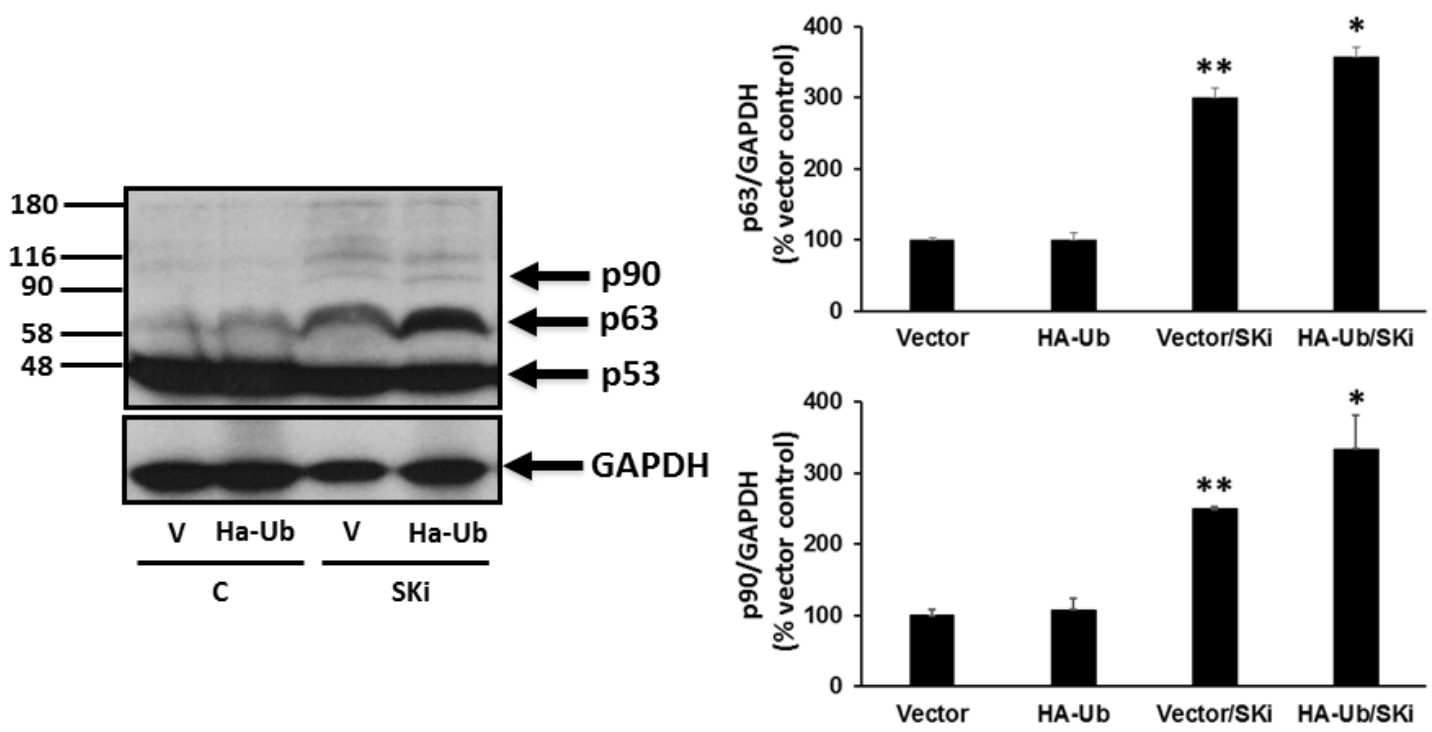

Fig. 3 The effect of the over-expression of ubiquitin on the SKi-induced formation of p63 and p90 in HEK293T cells. Cells maintained in serum were transfected with vector or HA-tagged ubiquitin plasmid construct for $24 \mathrm{~h}$ and then grown to $70 \%$ confluence before being treated with SKi $(10 \mu \mathrm{M})$ for $24 \mathrm{~h}$. Western blot probed with anti-p53 antibody showing the stimulatory effect of over-expressing HA-tagged ubiquitin on the formation of p63 and p90 in response to SKi. Blots were re-probed for GAPDH using anti-GAPDH antibody to ensure comparable protein loading. Results are representative of at least 3 independent experiments. Also shown is the densitometric 
quantification of p63/GAPDH and p90/GAPDH ratios expressed as a percentage of the control (Control=100\%). The data was expressed as means $+/-$ SEM for $n=3$ experiments and analysed by one-way ANOVA and Bonferroni’s multiple comparisons test, * $\mathrm{p}<0.05$ for HA-Ub/SKi versus vector/SKi and ${ }^{* *} \mathrm{p}<0.01$ for vector/SKi versus Vector.

The ubiquitination of p53 tags this protein for degradation by the proteasome. We therefore hypothesised that treatment of the cells with a proteasome inhibitor, MG132, might enhance the formation of p63 and p90 in response to SKi as p63 and p90 will not be degraded under these conditions and will therefore accumulate. However, pre-treatment of HEK293T cells with MG132 paradoxically abolished the SKi-induced formation of p63 and p90 (Fig. 4A). This finding suggests that SKi might promote the proteasomal degradation and removal of a different unidentified protein that normally suppresses the conversion of p53 to p63/p90 and which likely accumulates in cells treated with MG132. A possible candidate for this protein is SK1 because the sphingosine kinase inhibitor, SKi, promotes the degradation of this enzyme and this can be reversed by MG132 in HEK293T cells [20]. The role of SK1 in regulating the conversion of p53 to p63 and p90 was examined by combining SK1 siRNA and SKi which completely abolished the expression of SK1 (Fig. 4B). Either agents alone induced a decrease in SK1 expression (each 80\%) (Fig. 4B). 


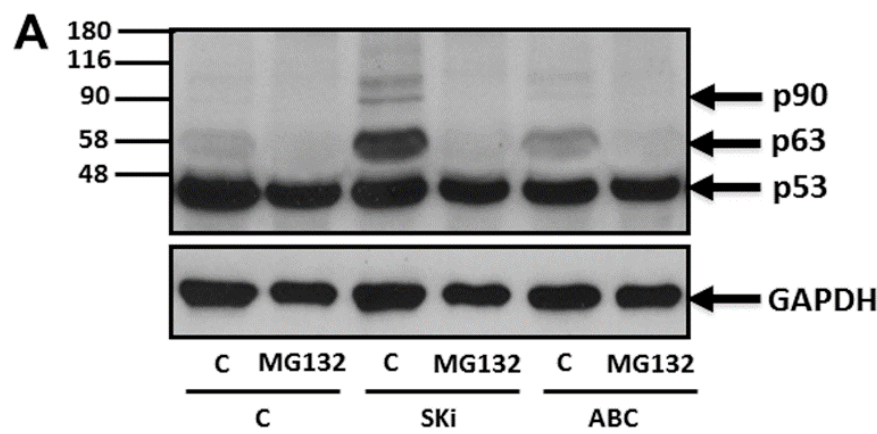

B

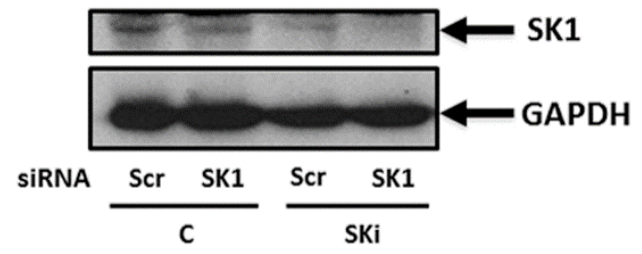

Fig. 4 The effect of the proteasome inhibitor, MG132, on the ubiquitination of p53 in HEK293T cells. Cells maintained in serum and grown to 70\% confluence were pre-treated with MG132 $(10 \mu \mathrm{M})$ prior to SKi $(10 \mu \mathrm{M})$ or ABC294640 $(25 \mu \mathrm{M})$ for $24 \mathrm{~h}$. (A) Western blot probed with anti-p53 antibody showing the effect of MG132 on the formation of p63 and p90 in response to SKi. (B) Cells maintained in serum and grown to $70 \%$ confluence were treated with scrambled siRNA or SK1 siRNA (100 nM) for $48 \mathrm{~h}$ prior to treatment with or without SKi (10 $\mu \mathrm{M}, 24 \mathrm{~h})$. Western blot probed with anti-SK1 antibody showing the effect of SKi and SK1 siRNA on SK1 expression. Blots were re-probed for GAPDH using anti-GAPDH antibody to ensure comparable protein loading. Results are representative of at least 3 independent experiments.

Combined treatment of cells with SK1 siRNA and SKi enhanced the formation of p63 and p90 (Fig. 5A) over and above the effect induced by SKi or siRNA SK1 alone. This data suggests that SK1 functions to limit the conversion of p53 into p63 and p90 in response to SKi. We have previously shown that SKi also promotes the polyubiquitination of Degs1 and inhibits SK2 activity [20]. Therefore, we assessed the effect of SK2 siRNA (which reduced SK2 mRNA transcript by 50\% [20]) or Degs1 siRNA (which reduced Degs1 protein expression by 80\% [20]) on p63 and p90 formation. However, neither had any effect (Fig. 5B, C). 

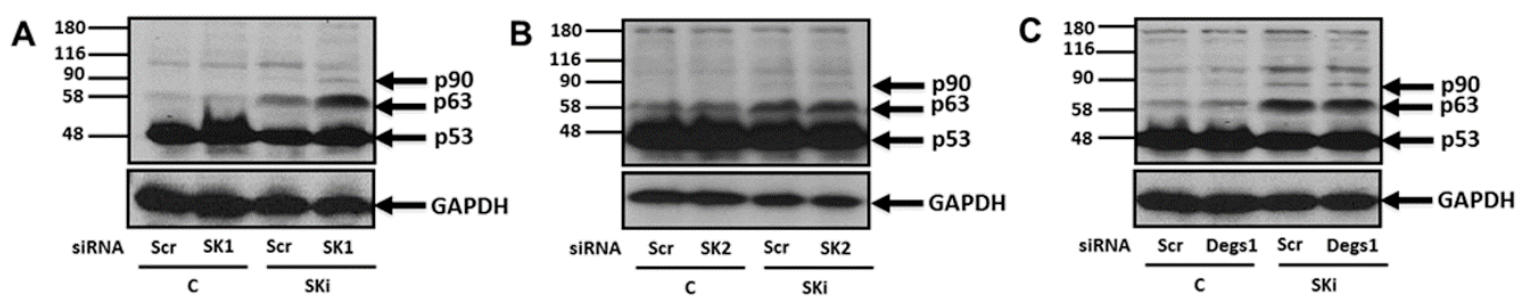

Fig. 5 Effect of SK1 or SK2 or Degs1 siRNA on the ubiquitination of p53 in HEK293T cells. Cells maintained in serum and grown to $70 \%$ confluence were treated with scrambled siRNA or SK1 or SK2 or Degs1 siRNA (100 nM) for 48 h prior to treatment with or without SKi $(10 \mu \mathrm{M})$ for $24 \mathrm{~h}$. Western blots probed with anti-p53 antibody showing the effect of (A) SK1 siRNA, (B) SK2 siRNA and (C) Degs 1 siRNA on the formation of p63 and p90 in response to SKi. Blots were re-probed for GAPDH using anti-GAPDH antibody to ensure comparable protein loading. Results are representative of at least 3 independent experiments.

3.2 The effect of NAC on p63/p90 formation--Previous studies have demonstrated that p53 function is intimately linked with oxidative stress [28]. We therefore assessed the effect of the anti-oxidant N-acetyl-cysteine (NAC) on the formation of p63 and p90. However, NAC had no effect (Fig. 6), thereby excluding the involvement of oxidative stress.

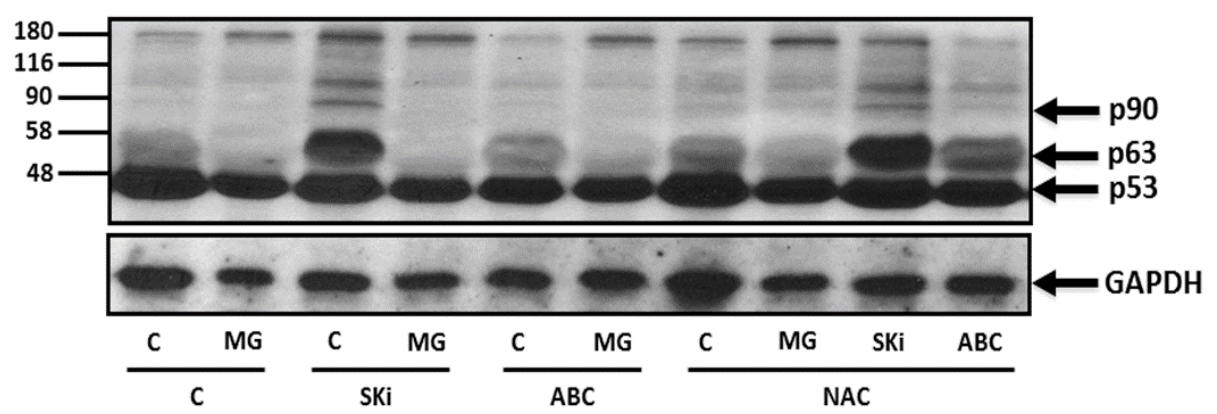

Fig. 6 Oxidative stress and ubiquitination of p53 in HEK293T cells. Cells maintained in serum and grown to $70 \%$ confluence were treated with NAC (10 mM) and/or MG132 (10 $\mu \mathrm{M})$ for 30 min prior to treatment with SKi $(10 \mu \mathrm{M})$ or ABC294640 $(25 \mu \mathrm{M})$ for $24 \mathrm{~h}$. Western blot probed with anti-p53 antibody showing the lack of effect of NAC on the post-translational modification of p53. Blots were re-probed for GAPDH using anti-GAPDH antibody to ensure comparable protein loading. Results are representative of at least 3 independent experiments. 
3.3 Effect of SKi on JNK/p38 MAPK--We have previously shown that the polyubquitinated forms of Degs1 positively regulate pro-survival p38 MAPK and JNK pathways in HEK293T cells [20]. Inhibitors of p38 MAPK and JNK pathways impede cell growth and promote PARP cleavage respectively in HEK293T cells [20]. Given that the substrate of Degs1, dihydroceramide is produced by CerS from the substrate dihydrosphingosine, and that SK can catalyse phosphorylation of dihydrosphingosine to form dihydroS1P, we investigated whether either SK1 or SK2 is involved in regulating the JNK or p38 MAPK pathways in HEK293T cells. In this regard, siRNA knockdown of SK1 but not SK2 enhanced the SKi-induced activation of p38 MAPK and JNK (Fig. 7A, B), thereby suggesting that SK1 functions to oppose these pro-survival signaling pathways in HEK293T cells. Knockdown of p53 was without effect on SKi-induced phosphorylation of p38 MAPK or JNK (Fig. 7C).

A
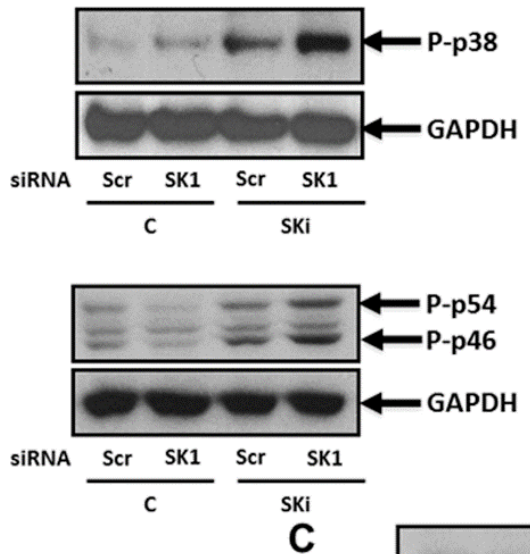

B
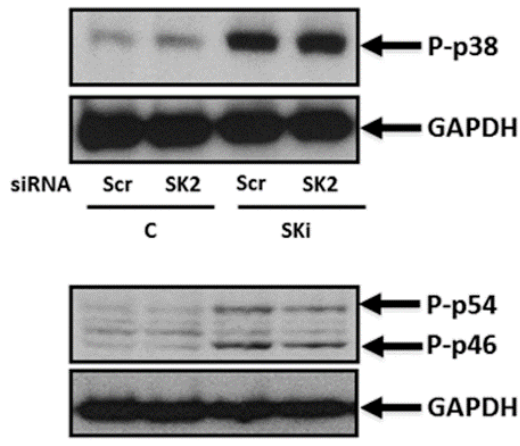

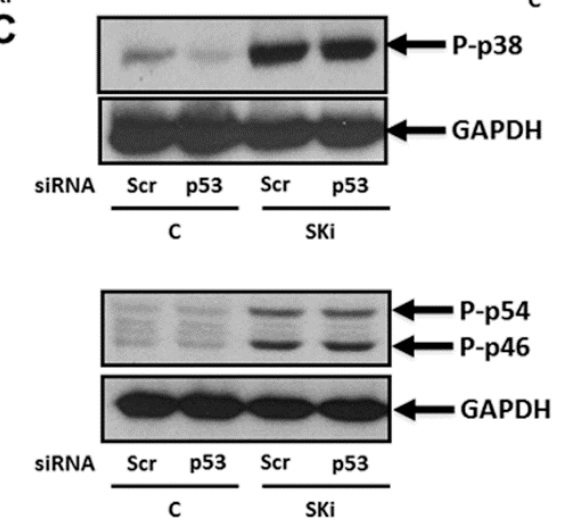


Fig. 7 p38 MAPK and JNK signalling in HEK293T cells. Cells maintained in serum and grown to $70 \%$ confluence were treated with scrambled siRNA or SK1 or SK2 or p53 siRNA (100 nM) for $48 \mathrm{~h}$ prior to treatment with or without SKi $(10 \mu \mathrm{M})$ for $24 \mathrm{~h}$. Western blots probed with antiphospho p38 MAPK or anti-phospho JNK antibody showing the effect of (A) SK1 siRNA, (B) SK2 siRNA and (C) p53 siRNA on the phosphorylation of p38 MAPK and JNK in response to SKi. Blots were re-probed for GAPDH using anti-GAPDH antibody to ensure comparable protein loading. Results are representative of at least 3 independent experiments.

3.4 p53 and PARP cleavage--The next question concerned the functional role of p53 in regulating PARP cleavage in HEK293T cells. We previously reported that SKi in HEK293T cells does not induce PARP cleavage; nor does it affect DNA synthesis [20]. Here we show that ABC294640 only very weakly stimulated formation of p63/p90 (Fig. 1, Fig. 4A), but does induce PARP cleavage and reduces DNA synthesis (Fig. 8A, B [20]). Both of these responses are reversed by siRNA knockdown of p53 expression (Fig. 8A, B).

We have also previously shown that the ABC294640-induced PARP cleavage in HEK293T cells is mediated by the native forms of Degs1 (i.e. the form that is not polyubiquitinated [20]). Therefore, both native Degs1 and p53 appear to function in concert to reduce the survival of HEK293T cells. The action of native p53 might relate to stimulation of the mitochondrial apoptotic pathway mediated by Apaf-1, which plays a significant role ER stress-induced apoptosis and which involves the BH3-only proteins, PUMA and NOXA, whose expression levels are regulated by p53 [29]. 

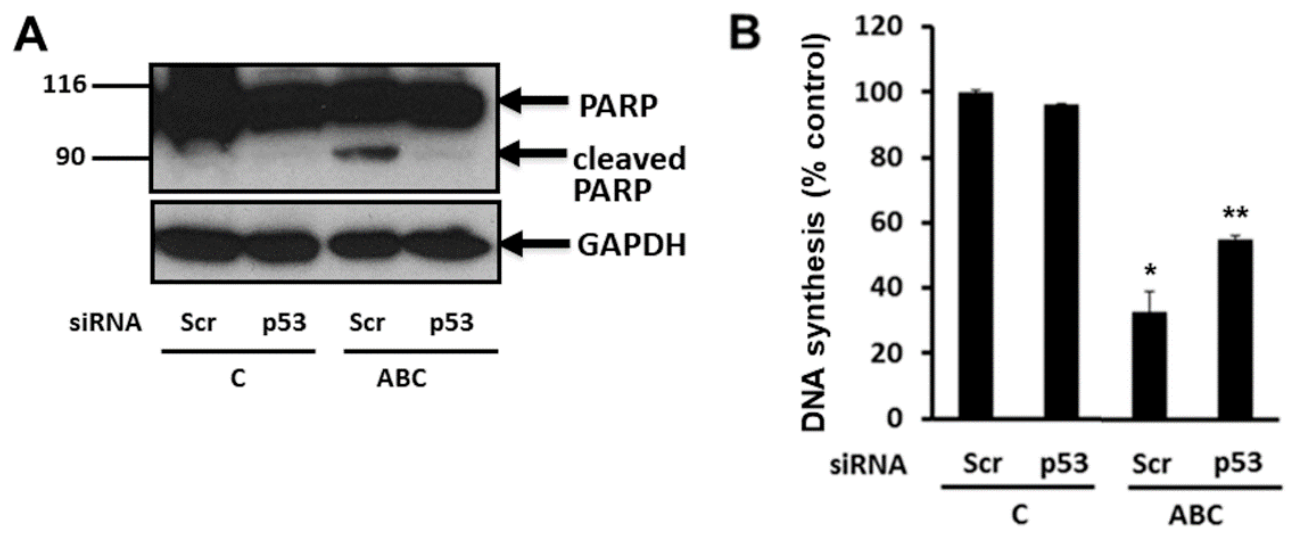

Fig. 8 Effect of ABC294640 on PARP cleavage and DNA synthesis in HEK293T cells. Cells maintained in serum and grown to $70 \%$ confluence were treated with scrambled siRNA or p53 siRNA (100 nM) for $48 \mathrm{~h}$ prior to treatment with or without ABC294640 (25 $\mu \mathrm{M})$ for $24 \mathrm{~h}$. (A) Western blot probed with anti-PARP antibody showing the effect of p53 siRNA on ABC294640induced PARP cleavage. The blot was re-probed for GAPDH using anti-GAPDH antibody to ensure comparable protein loading. Results are representative of at least 3 independent experiments. (B) Bar graph showing the effect of p53 siRNA on the ABC294640-induced decrease in DNA synthesis. The data was analysed by one-way ANOVA multiple comparisons, * $\mathrm{p}<0.0001$ for scrambled versus scrambled/ABC294640; ** $\mathrm{p}<0.0001$ for scrambled siRNA/ABC294640 versus p53 siRNA/ABC294640. Data $\left({ }^{3} \mathrm{H}\right]$ thymidine incorporation (dpm)) are means \pm SD for three independent experiments.

3.5 Role of p53 in regulating XBP-1s--One mechanism by which sphingosine kinases might regulate cell survival is via endoplasmic reticulum (ER) stress, as lipid composition in the ER membrane can activate an ER stress responses [13, 30, 31]. Recent studies have demonstrated that ABC294640 and another SK2 inhibitor, K145 [32], induce ER stress with the latter increasing expression of XBP-1s and p-eIF2a [33]. Targeting SK2 with K145 also contributed to ER stress induced by bortezomib, as evidenced by stimulation of the IRE1, JNK and p38 MAPK pathways, thereby resulting in potent synergistic apoptosis of myeloma cells in vitro [33]. We have previously shown that SKi enhances MG132-stimulated expression of the pro-survival protein, X-box binding protein 1s (XBP-1s) in HEK293T cells and that this involves polyubiquitinated Degs1 [20]. We therefore investigated the role of SK1 and SK2 in regulating this process. Treatment of HEK293T 
cells with SK1 siRNA reduced the expression of XBP-1s induced by MG132 but had no effect on the enhancement of MG132-stimulated XBP-1s expression by SKi (Fig. 9A). In contrast, siRNA knockdown of SK2 reduced the MG132-induced XBP-1s expression and the enhancement caused by SKi (Fig. 9B). Although ABC294640 is an inhibitor of SK2, it is in fact a very weak one, and paradoxically significantly up-regulates the biosynthesis of ceramide, sphingosine and S1P in HEK293T cells [20]. Therefore, SK2 might be involved in promoting XBP-1s expression in response to proteasome inhibition with MG132, i.e. SK2 behaves in a pro-survival context. The differential effect of SK1 knockdown on MG132- and SKi/MG132-induced XBP-1s expression is likely due to the fact that Degs1 appears to have a more significant role than SK1 in mediating the effect of SKi, in terms, of potentiating the action of MG132 on XBP-1s expression [20]. Therefore, there appears to be a switch in reliance from SK1 to Degs1 in response to MG132 and MG132/SKi respectively. Whether this is due to re-localisation of SK1 to a different cellular compartment in response to SKi requires further study. SK1 has to be localised to the proteasome at some point in order to be degraded by it. In contrast, there is no change in the role of SK2, with a requirement in cells treated with either MG132 or MG132/SKi.

In addition, siRNA knockdown of p53 enhanced the increase in XBP-1s expression induced by MG132 and by MG132/SKi (Fig. 9C), suggesting that the native form of p53 restricts formation of pro-survival XBP-1s. Treatment of HEK293T cells with MG132 also induced PARP cleavage and this was reduced by siRNA knockdown of p53 (Fig. 9F), thereby linking p53-mediated suppression of XBP-1s expression with PARP cleavage. None of these effects involve p63/p90 as their formation is inhibited by MG132 (Fig. 4A). The siRNA knockdown of SK1 or SK2 had no effect on the MG132-induced PARP cleavage (Fig. 9D, E), suggesting that in the context of p53induced cell death, p53 is already maximally effective in inducing this death promoting pathway. 

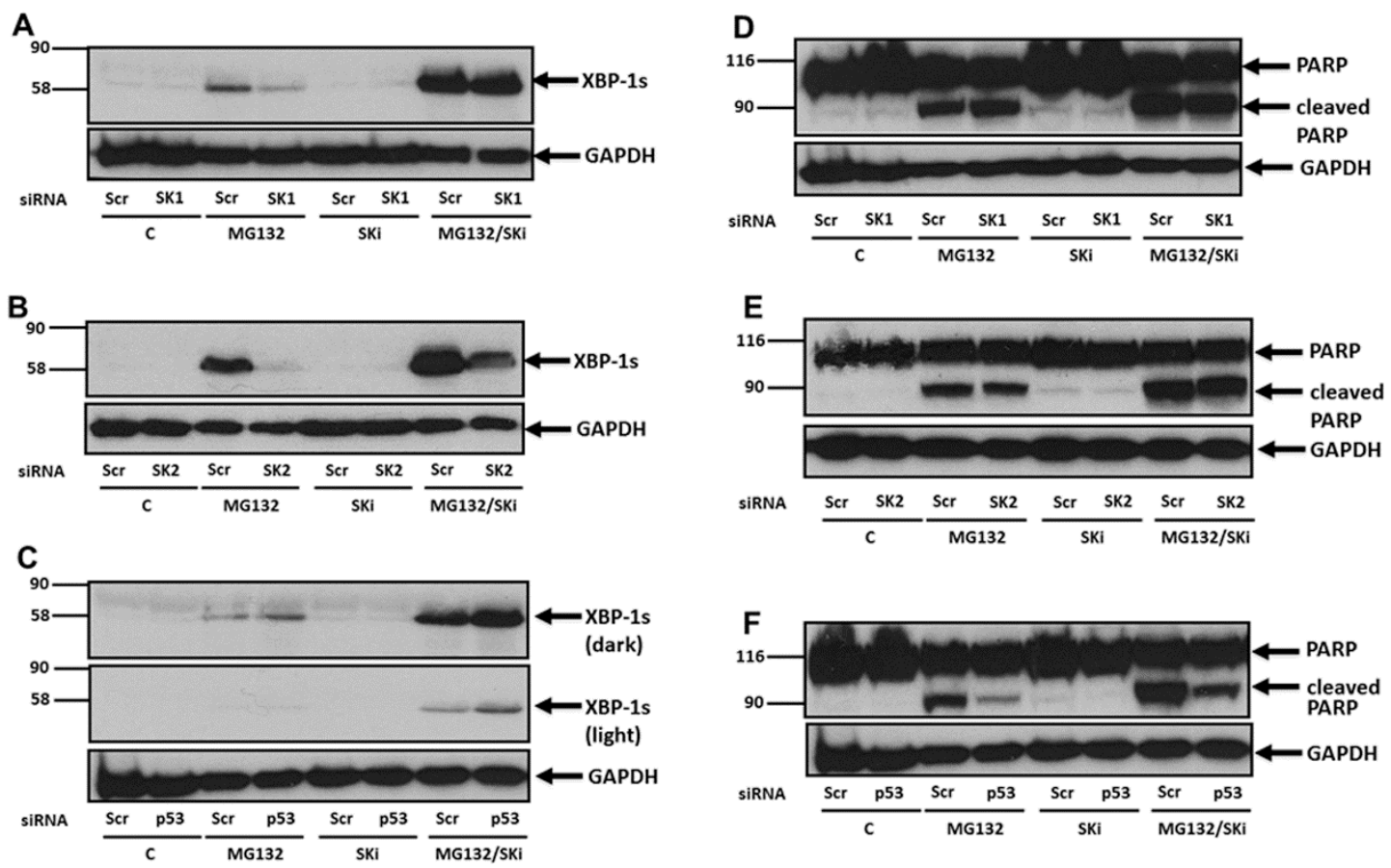

Fig. 9 Regulation of XBP-1s expression and PARP cleavage in HEK293T cells. Cells maintained in serum and grown to 70\% confluence were treated with scrambled siRNA or SK1 or SK2 or p53 siRNA (100 nM) for 48 h prior to pre-treatment with MG132 (10 $\mu \mathrm{M})$ for 30 min, where indicated, and with or without SKi $(10 \mu \mathrm{M})$ for $24 \mathrm{~h}$. Western blots probed with anti-XBP1s antibody showing the effect of (A) SK1 siRNA or (B) SK2 siRNA or (C) p53 siRNA treatment on the induction of XBP-1s by MG132 in the presence and absence of SKi. A lighter exposed XBP-1s blot is shown to better typify the increase in XBP-1s expression with p53 siRNA. Western blots were also probed with anti-PARP antibody showing the effect of (D) SK1 siRNA or (E) SK2 siRNA or (F) p53 siRNA treatment on the PARP cleavage induced by MG132 in the presence and absence of SKi. Blots were re-probed for GAPDH using anti-GAPDH antibody to ensure comparable protein loading. Results are representative of at least 3 independent experiments.

3.6 Sphingolipid levels--We next measured changes in sphingolipid levels to establish any association with the observed alterations in p38 MAPK, JNK and XBP-1s signaling. Treatment of HEK293T cells with scrambled siRNA and SKi induced an increase in the levels of dihydroceramide species and this was mirrored by similar increases in dihydrosphingomyelin levels (Fig. 10A). These findings are consistent with the SKi-induced ubiquitin-proteasomal degradation of Degs1 [20]. However, combined treatment of cells with SKi and SK1 siRNA, 
which abolished SK1 expression, had no enhancing effect on the formation of dihydroceramide or dihydrosphingomyelin (Fig. 10A). There were also no significant changes in the levels of ceramide or sphingomyelin (Fig 10A) and therefore, the enhanced p38 MAPK/JNK signaling in response to SKi in cells in which SK1 has been completely removed (Fig. 7A) (by combined treatment with SKi and SK1 siRNA (Fig. 4B)) cannot be accounted for, by changes in dihydroceramide/ceramide levels. On the contrary, combined treatment of HEK293T cells with SKi and SK1 siRNA significantly increased sphingosine levels and decreased S1P levels (versus scrambled siRNA/SKi) (Fig. 10B), suggesting that these changes might be associated with enhanced p38 MAPK/JNK signaling. However, the changes in sphingosine/S1P levels are very small and this might reflect compensation by SK2 or that a discrete pool of intracellular S1P regulated by SK1 is affected and this requires further investigation. 

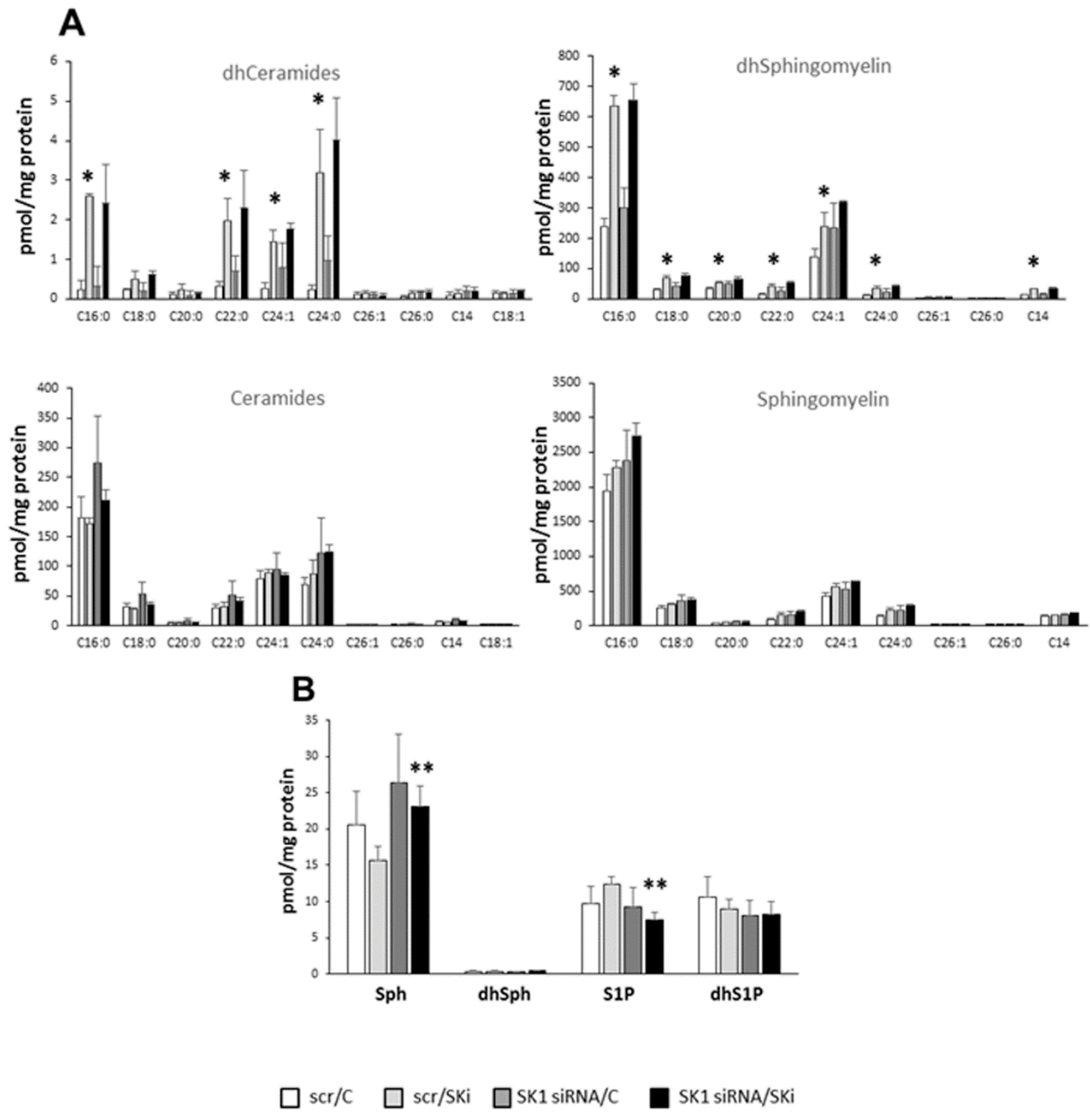

Fig. 10 Effect of SK1 siRNA and SKi on sphingolipid levels in HEK293T cells. Cells maintained in serum and grown to $70 \%$ confluence were treated with scrambled or SK1 siRNA $(100 \mathrm{nM})$ for $48 \mathrm{~h}$ prior to treatment with or without SKi $(10 \mu \mathrm{M})$ for $24 \mathrm{~h}$, followed by snapfreezing. Lipid extracts were analysed by LC-MS for different molecular species of (A) dihydroceramide, dihydrosphingomyelin, ceramide or sphingomyelin and (B) sphingoid bases. In (A) the $\mathrm{x}$-axis annotates different $\mathrm{N}$-acyl chain lengths and double bond molecular species. $\left({ }^{*} \mathrm{p}<\right.$ 0.05 for scrambled/SKi versus scrambled/control; ** $\mathrm{p}<0.05$ for SK1 siRNA/SKi versus scrambled/SKi; data are means \pm SD for three independent samples. 
Treatment of HEK293T cells with SK2 siRNA had no effect on the levels of dihydroceramide species and did not enhance the effect of SKi on these sphingolipids (Fig. 11A). However, treatment of HEK293T cells with SK2 siRNA did significantly increase the levels of multiple species of ceramide and sphingomyelin (Fig. 11A). These changes in ceramides, which are, in some cases, likely to be pro-apoptotic, suggest a pro-survival function for SK2 and are consistent with the effect of SK2 knockdown in reducing XBP-1s expression (Fig. 9B). In contrast with SK1 siRNA/SKi, the combined treatment of cells with SK2 siRNA and SKi had no effect on sphingoid base levels (Fig. 11B). 
A
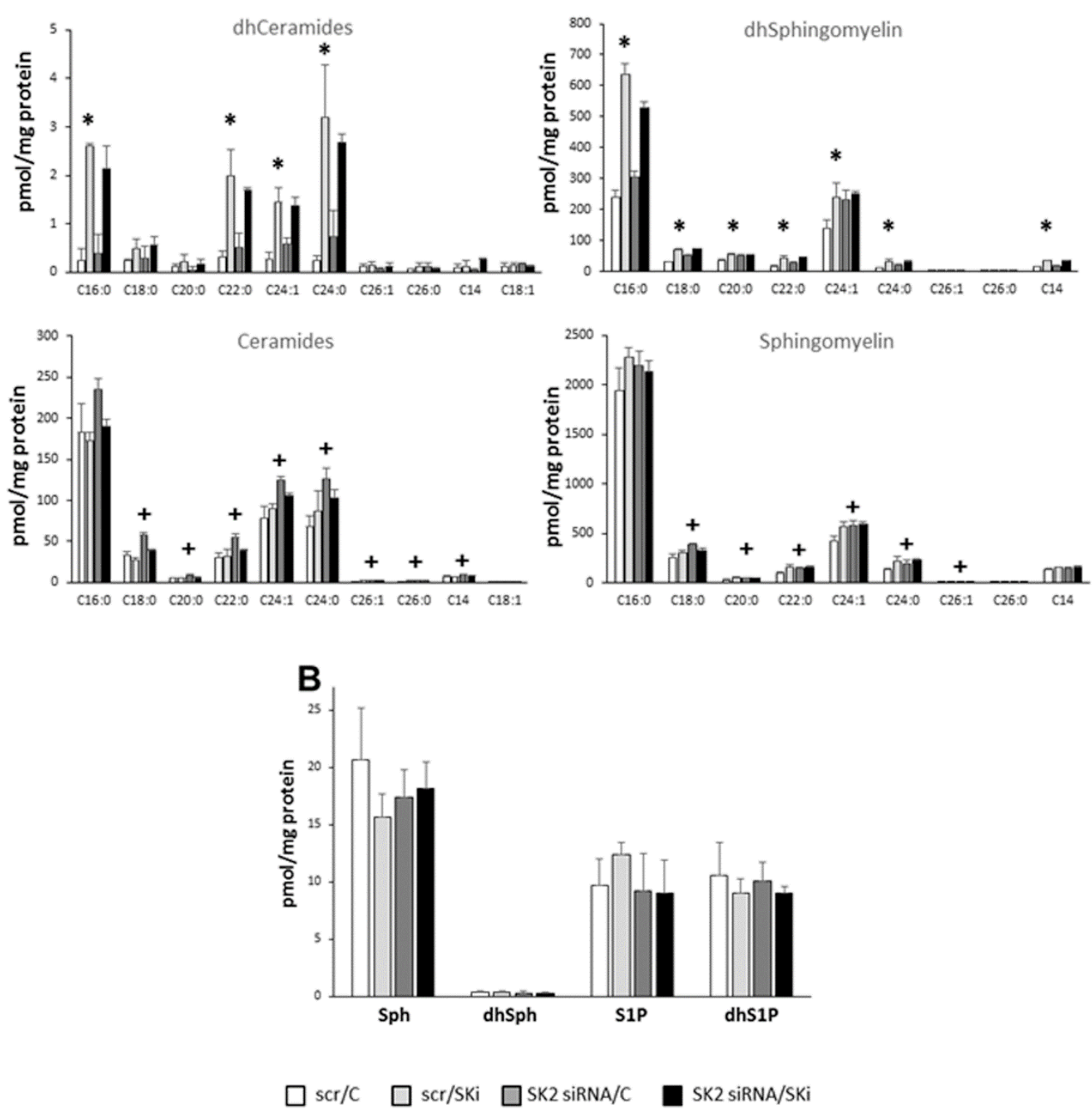

Fig. 11 Effect of SK2 siRNA and SKi on sphingolipid levels in HEK293T cells. Cells maintained in serum and grown to $70 \%$ confluence were treated with scrambled or SK2 siRNA $(100 \mathrm{nM})$ for $48 \mathrm{~h}$ prior to treatment with SKi $(10 \mu \mathrm{M})$ for $24 \mathrm{~h}$, followed by snap-freezing. Lipid extracts were analysed by LC-MS for different molecular species of (A) dihydroceramide, dihydrosphingomyelin, ceramide or sphingomyelin and (B) sphingoid bases. In (A) the x-axis annotates different $\mathrm{N}$-acyl chain lengths and double bond molecular species. ( $* \mathrm{p}<0.05$ for scrambled/SKi versus scrambled/control; $+\mathrm{p}<0.05$ for SK2 siRNA/control versus scrambled/control; data are means \pm SD for three independent samples. 


\section{Conclusion}

These findings suggest that SK1 limits conversion of p53 into p63/p90 in response to SKi and opposes activation of pro-survival p38 MAPK/JNK signaling in HEK293T cells. In contrast, SK2 is involved in promoting pro-survival XBP-1s expression, and which is opposed by native p53 in HEK293T cells (Fig. 12). Future studies are required to further validate p63 and p90 as p53derived intermediates on route to proteasomal degradation which, if the case, might lead to loss of function of p53 in promoting cell death.

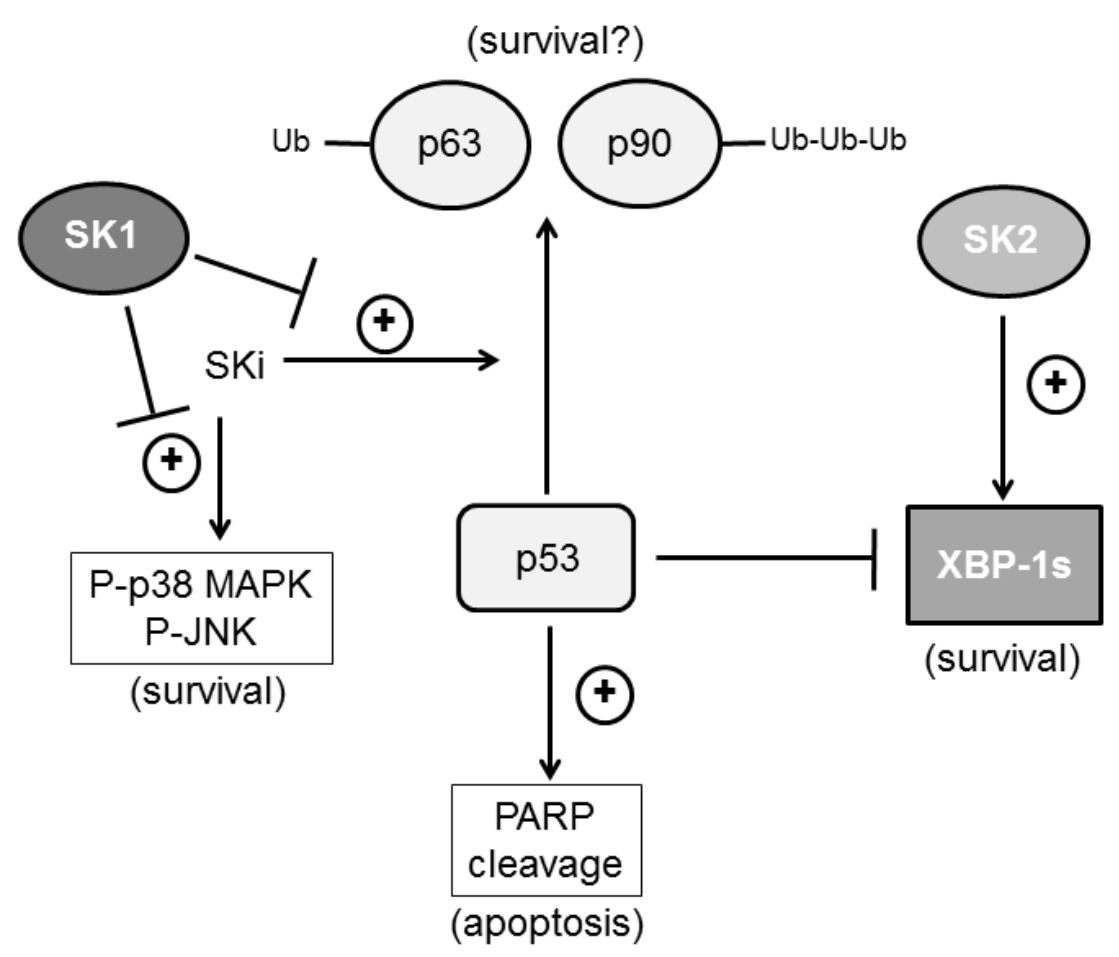

Fig. 12 Scheme depicting ubiquitination of p53 in response to SKi in HEK293T cells. SKi promotes conversion of p53 into p63 and p90 which, together with phosphorylated p38 MAPK and phosphorylated JNK might promote survival of HEK93T cells. SK1 counters these effects. In contrast, SK2 supports survival of these cells by promoting XBP-1s expression.

\section{Acknowledgement}

MA thanks the Kuwait Government for PhD sponsorship (Ref number, 1590235272). 


\section{References}

1. S. Pyne, D.R. Adams, N.J. Pyne, Sphingosine 1-phosphate and sphingosine kinases in health and disease: Recent advances. Prog. Lipid Res. 62 (2016) 93-106.

2. V.A. Blaho VA, T. Hla, An update on the biology of sphingosine 1-phosphate receptors. J. Lipid Res. 55 (2104) 1596-608.

3. N.C. Hait, J. Allegood, M. Maceyka, G.M. Strub, K.B. Harikumar, S.K. Singh, C. Luo, R. Marmorstein, T. Kordula, S. Milstien, S. Spiegel, Regulation of histone acetylation in the nucleus by sphingosine-1-phosphate. Science 325 (2009), 1254-1257.

4. G.M. Strub, M. Paillard, J. Liang, I. Gomez, J.C. Allegood, N.C. Hait, M. Maceyka, M.M. Price, Q. Chen, D.C. Simpson, T. Kordula, S. Milstien, E.J. Lesnefsky, S. Spiegel, Sphingosine-1-phosphate produced by sphingosine kinase 2 in mitochondria interacts with prohibitin 2 to regulate complex IV assembly and respiration. FASEB J. 25 (2011) 600-612.

5. S. Lima, K. Takabe, J. Newton, K. Saurabh, M.M. Young, A.m. Leopoldino, N.C. Hait, J.l. Roberts, H.G. Wang, P. Dent, S. Milstien, L. Booth, S. Spiegel S, TP53 is required for BECN1- and ATG5-dependent cell death induced by sphingosine kinase 1 inhibition. Autophagy 11 (2018) 1-16.

6. M. McNaughton, M. Pitman, S.M. Pitson, N.J. Pyne, S. Pyne, Proteasomal degradation of sphingosine kinase 1 and inhibition of dihydroceramide desaturase by the sphingosine kinase inhibitors, SKi or ABC294640, induces growth arrest inandrogen-independent LNCaP-AI prostate cancer cells. Oncotarget 7 (2016)16663-16675.

7. H. Venant, M. Rahmaniyan, E.E. Jones, P. Lu, M.B. Lilly, E. Garrett-Mayer, R.R. Drake, J.M. Kraveka, C.D, Smith, C. Voelkel-Johnson C, The sphingosine kinase 2 inhibitor ABC294640 reduces the growth of prostate cancer cells and results in accumulation of dihydroceramides in vitro and in vivo. Mol. Cancer Ther. 14 (2015) 2744-2752. 
8. G. Illuzzi, C. Bernacchioni, M. Aureli, S. Prioni, G. Frera, C. Donati, M. Valsecchi, V. Chigorno, P. Bruni, S. Sonnino, A. Prinetti , Sphingosine kinase mediates resistance to the synthetic retinoid N-(4-hydroxyphenyl)retinamide in human ovarian cancer cells. J. Biol. Chem. 285 (2010) 18594-18602.

9. C. Loveridge, F. Tonelli, T. Leclercq, K.G. Lim, J.S. Long, E. Berdyshev, R.J. Tate, V. Natarajan, S.M. Pitson, N.J. Pyne, S. Pyne, The sphingosine kinase 1 inhibitor 2-(phydroxyanilino)-4-(p-chlorophenyl)thiazole induces proteasomal degradation of sphingosine kinase 1 in mammalian cells. J. Biol. Chem. 285 (2010) 38841-38852.

10. F. Cingolani, M. Casasampere, P. Sanllehí, J. Casas, J. Bujons, G. Fabriàs, Inhibition of dihydroceramide desaturase activity by the sphingosine kinase inhibitor SKI II. J. Lipid Res. 55 (2014) 1711-1720.

11. B.L. Carroll, J. Bonica, A.A. Shamseddine, Y.A. Hannun, L.M. Obeid LM, A role for caspase-2 in sphingosine kinase 1 proteolysis in response to doxorubicin in breast cancer cells - implications for the CHK1-suppressed pathway. FEBS Open Bio. 8 (2017) 27-40.

12. M.M. Siddique, Y. Li, L. Wang, J. Ching, M. Mal, O. Ilkayeva, Y.J. Wu, B.H. Bay, S. Summers, Ablation of dihydroceramide desaturase 1, a therapeutic target for the treatment of metabolic diseases, simultaneously stimulates anabolic and catabolic signaling. Mol. Cell Biol. 33 (2013) 2353-2369.

13. V. Gagliostro, J. Casas, A. Caretti, J.L. Abad, L. Tagliavacca, R. Ghidoni, G. Fabriàs, P. Signorelli P, Dihydroceramide delays cell cycle G1/S transition via activation of ER stress and induction of autophagy. Int. J. Biochem. Cell Biol. 44 (2012) 2135-2143.

14. S. Hernández-Tiedra, G. Fabriàs, D. Dávila, ÍJ Salanueva, J. Casas, L.R. Montes, Z. Antón, E. García-Taboada, M. Salazar-Roa, M. Lorente, J. Nylandsted, J. Armstrong, I. LópezValero, C.S. McKee, A. Serrano-Puebla, R. García-López, J. González-Martínez, J.L. Abad, K. Hanada, P. Boya, F. Goñi, M. Guzmán, P. Lovat, M. Jäättelä, A. Alonso, G. Velasco, 
Dihydroceramide accumulation mediates cytotoxic autophagy of cancer cells via autolysosome destabilization. Autophagy 12 (2016) 2213-2229.

15. J.M. Wu, A.M. DiPietrantonio, T.C. Hsieh T, Mechanism of fenretinide (4-HPR)-induced cell death. Apoptosis 6 (2001) 377-88.

16. A. Erdreich-Epstein, L.B. Tran, N.N. Bowman, H. Wang, M.C. Cabot, D.L. Durden, J. Vlckova, C.P. Reynolds, M.F. Stins, S. Groshen, M. Millard, Ceramide signaling in fenretinide-induced endothelial cell apoptosis. J. Biol. Chem. 277 (2002)49531-49537.

17. N. HailJr, H.J. Kim, R. Lotan R, Mechanisms of fenretinide-induced apoptosis. Apoptosis 11 (2006) 1677-94.

18. H. Liu, R.E, Toman, S.K. Goparaju, M. Maceyka, V.E. Nava, H. Sankala, S.G. Payne, M. Bektas, I. Ishii, J. Chun, S. Milstien, S. Spiegel, Sphingosine kinase type 2 is a putative BH3only protein that induces apoptosis. J. Biol. Chem. 278 (2003) 40330-40336.

19. S. Pyne, D.R. Adams, N.J. Pyne, Sphingosine Kinases as Druggable Targets. Handb Exp Pharmacol. 2018 (doi: 10.1007/164_2018_96).

20. M. Alsanafi, S.L. Kelly, K. Jubair, M. McNaughton, R.J. Tate, A.H. Jr. Merrill, S. Pyne, N.J. Pyne, Native and polyubiquitinated forms of dihydroceramide desaturase are differentially linked with either cell survival or apoptosis in human embryonic kidney cells. Mol Cell Biol (2018) 38. pii: e00222-18.

21. P. Sridevi, H. Alexander, E.L. Laviad, J. Min, A. Mesika, M. Hannink, A.H. Futerman, S. Alexander, Stress-induced ER to Golgi translocation of ceramide synthase 1 is dependent on proteasomal processing. Exp. Cell Res. 316 (2010) 78-91.

22. J. Min, A. Mesika, M. Sivaguru, P.P. Van Veldhoven, H. Alexander, A.H. Futerman, S. Alexander S, (Dihydro)ceramide synthase 1 regulated sensitivity to cisplatin is associated with the activation of p38 mitogen-activated protein kinase and is abrogated by sphingosine kinase 1. Mol. Cancer Res. 5 (2007) 801-812. 
23. K.J. French, R.S. Schrecengost, B.D. Lee, Y. Zhuang, S.N. Smith, J.L. Eberly, J.K. Yun, C.D. Smith, Discovery and evaluation of inhibitors of human sphingosine kinase. Cancer Res. 63 (2003) 5962-5969.

24. K.J. French, Y. Zhuang, L.W. Maines, P. Gao, W. Wang, V. Beljanski, J.J. Upson, C.L. Green, S.N. Keller, C.D. Smith, Pharmacology and antitumor activity of ABC294640, a selective inhibitor of sphingosine kinase-2. J. Pharmacol. Exp. Ther. 333 (2010)129-139.

25. N. MacRitchie, G. Volpert, M. Al Washih, D.G. Watson, A.H. Futerman, S. Kennedy, S. Pyne, N.J. Pyne, Effect of the sphingosine kinase 1 selective inhibitor, PF-543 on arterial and cardiac remodelling in a hypoxic model of pulmonary arterial hypertension. Cell. Signal. 28 (2016) 946-55.

26. R.L. Shaner, J.C. Allegood, H. Park, E. Wang, S. Kelly, C.A. Haynes, M.C. Sullards, A.H. Jr Merrill, Quantitative analysis of sphingolipids for lipidomics using triple quadrupole and quadrupole linear ion trap mass spectrometers. J. Lipid Res. 50 (2009) 1692-707.

27. M.C. Sullards, Y. Liu, Y. Chen, AH Jr. Merrill, Analysis of mammalian sphingolipids by liquid chromatography tandem mass spectrometry (LC-MS/MS) and tissue imaging mass spectrometry (TIMS). Biochim Biophys Acta. 1811 (2011) 838-853.

28. A. Vigneron, K.H. Vousden, p53, ROS and senescence in the control of aging. Aging 2 (2010) 471-4.

29. J. Li, B. Lee, A.S. Lee, Endoplasmic reticulum stress-induced apoptosis: multiple pathways and activation of p53-up-regulated modulator of apoptosis (PUMA) and NOXA by p53. J. Biol. Chem. 281 (2006) 7260-7270.

30. S.D. Spassieva, T.D. Mullen, D.M. Townsend, L.M. Obeid, Disruption of ceramide synthesis by CerS2 down-regulation leads to autophagy and the unfolded protein response. Biochem. J. 424 (2009) 273-283. 
31. R. Volmer, D. Ron, Lipid-dependent regulation of the unfolded protein response. Curr. Opin. Cell Biol. 33 (2015) 67-73.

32. K. Liu, T.L. Guo, N.C. Hait, J. Allegood, H.i. Parikh, W. Xu, G.E. Kellogg, S. Grant, S. Spiegel, S. Zhang S, Biological characterization of 3-(2-amino-ethyl)-5-[3-(4-butoxylphenyl)- propylidene]-thiazolidine-2,4-dione (K145) as a selective sphingosine kinase-2 inhibitor and anticancer agent, PLoS One (2013) 8 e56471.

33. C.T. Wallington-Beddoe, M.K. Bennett, K. Vandyke, L. Davies, J.R. Zebol, P.A.B. Moretti, M.R. Pitman, D.R. Hewett, A.C.W. Zannettino, Pitson, S.M., Sphingosine kinase 2 inhibition synergises with bortezomib to target myeloma by enhancing endoplasmic reticulum stress. Oncotarget 8 (2017) 43602-43616. 